\title{
Chemical-quantum determination of the
}

\section{interaction type of leflunomide and collagen and its influence on arthritis}

\author{
Moisés Briteño Vázquez ${ }^{1}$, Dónovan González Martínez², Verónica Rodríguez \\ Soria $^{3}$, Laura Contreras Mioni ${ }^{3}$, Eva Luz González Martínez ${ }^{4}$, Manuel \\ González Pérez ${ }^{5}$
}

\author{
${ }^{1}$ Departamento de Fisioterapia, Benemérita Universidad Autónoma de Puebla (BUAP), México \\ Email: moybrit@hotmail.com \\ ${ }^{2}$ UTEL Universidad. Estudiante De Ingeniería En Ciencias Computacionales. Ciudad De México \\ Email: cernunnos94@outlook.com \\ ${ }^{3}$ Universidad Popular Autónoma del Estado de Puebla (UPAEP). Decanato de ciencias biológic as. \\ ${ }^{4}$ Bachillerato, Plantel Santiago 1.UPAEP. \\ Email: evaluz.gonzalez@upaep.edu.mx \\ ${ }^{5}$ Posgrado en ciencias de la Ingeniería Biomédica, UPAEP, México \\ Email: manuel.gonzalez@upaep.mx
}

\begin{abstract}
In recent years, researchers have evaluated the clinical efficacy and safety of Leflunomide (LEF) and other medications for the treatment of rheumatoid arthritis (RA). The objective of this work was chemicalquantum calculus and determination of the interaction type of LEF and collagen and its influence on arthritis. We obtained the information about the collagen of The National Center for Biotechnology Information (NCBI). It was obtained the formula of the LEF on the page of PubChem. The quantum calculations we carry out with the hyperchem software. These calculations were made in other articles already published by us. We concluded that 13 interactions of 40 calculated are significant. These 13 interactions show that only two of them are oxidant and the other 11 are reductive.
\end{abstract}

Keywords- Quantum chemistry, Leflunomide, Collagen, Arthritis, Amino Acid.

\section{INTRODUCTION}

In recent years, researchers have evaluated the clinical efficacy and safety of LEF (figure 1) and other medications for the treatment of rheumatoid artitis (RA). In their results, they announced that, in the treatment of RA with these combinations, it presented the characteristics of remarkably lowering the levels of laboratory indices. [1-3] In other studies, it was concluded that a weekly dose of $50 \mathrm{mg}$ of LEF showed similar benefits to the $10 \mathrm{mg}$ daily dose of the same medication in the treatment of moderate to moderate rheumatoid arthritis. [4] We also compared the short-term efficacy of
LEF and Methotrexate in the treatment of RA and did not find significant statistical differences. [5] They evaluated the clinical efficacy and safety of LEF as a new immunosuppressive medicine in lupus nephritis through a meta-analysis. LEF is a promising therapy for the treatment of lupus nephritis, mainly because of the efficacy and favorable safety profile determined by a meta-analysis. [6]

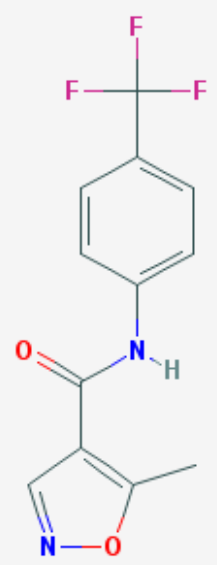

Fig.1: Leflunomide. IUPAC Name: 5-methyl-N-[4(trifluoro methyl) phenyl]-1,2-oxazole-4-carboxamide

A proportion of patients who achieved significant clinical benefit after an adequate trial of LEF was evaluated. A significant proportion of patients, most of whom had previously failed treatment with methotrexate, were able to respond to the disease with $\mathrm{LEF}$ with a low risk of adverse effects, suggesting that treatment with LEF may be a reasonable and cost-effective strategy in the face of 
biological therapy. [7] It was also shown that LEF could reduce the signs and symptoms of rheumatoid arthritis (RA) with regression in structural damage. Lung involvement is one of the extra-joint manifestations of rheumatoid arthritis and can occur due to any disease itself, or with medications used in the treatment. They presented 4 cases with rheumatoid arthritis that developed pulmonary nodules with LEF therapy. [8] On the other hand, a retrospective study was carried out evaluating the side effects of LE Fin 40 patients. LEF therapy was maintained in all patients and hypoglycemia regressed at variable intervals of no more than six months. They investigated that the active metabolite of LEF A77 1726, was able to block pre-established cardiac hypertrophy in mice. Other researchers, investigated the protective effects of LEF as a new immunosuppressant, on interstitial tubule lesions in a model of diabetic nephropathy in rats. These findings suggest that LEF protects the renal lesion of diabetic rats and that it could through the inhibition of OPN / TGF-b1 (osteopontin / beta 1 growth factor) mediated by extracellular cells, matrix deposition and tubulointerstitial fibrosis, as well as its inhibition on myofibroblast epithelial tubular transdifferentiation. [9]

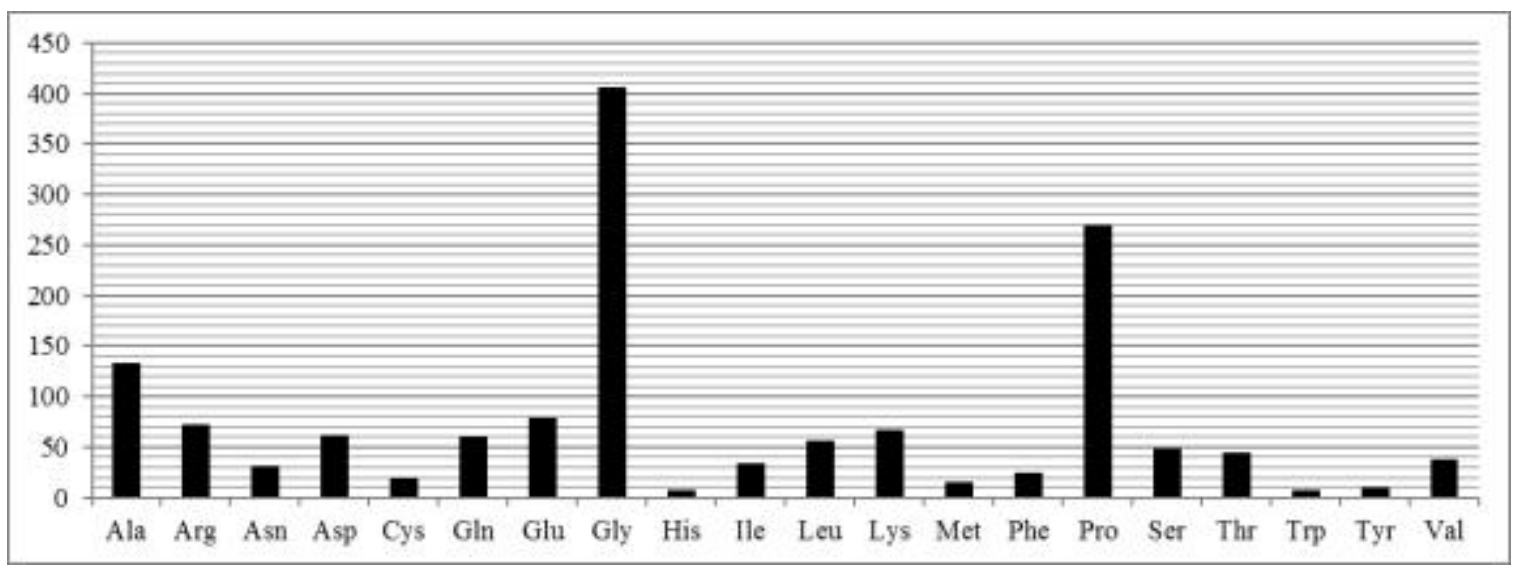

Fig.2: Graph of the amino acid content of human collagen.

Table.1: Calculation of the ETCs of the LEF in comparison with molecularoxygen and water.

\begin{tabular}{|c|c|c|c|c|c|c|c|c|c|}
\hline No & $\begin{array}{c}\text { Reducing } \\
\text { agent }\end{array}$ & $\begin{array}{c}\text { Oxidizing } \\
\text { agent }\end{array}$ & HOMO & LUMO & BG & E & E+ & EP & ETC \\
\hline 1 & $\mathrm{O}_{2}$ & $\mathrm{H}_{2} \mathrm{O}$ & -10.733 & 4.059 & 14.792 & -0.038 & 0.171 & 0.209 & 70.775 \\
\hline 2 & $\mathrm{O}_{2}$ & $\mathrm{LEF}$ & -10.733 & -0.484 & 10.249 & -0.038 & 0.140 & 0.178 & 57.579 \\
\hline 3 & $\mathrm{O}_{2}$ & $\mathrm{O}_{2}$ & -10.733 & -0.982 & 9.751 & -0.038 & 0.138 & 0.176 & 55.403 \\
\hline 4 & $\mathrm{H}_{2} \mathrm{O}$ & $\mathrm{H}_{2} \mathrm{O}$ & -12.316 & 4.059 & 16.375 & -0.127 & 0.171 & 0.298 & 54.950 \\
\hline 5 & $\mathrm{H}_{2} \mathrm{O}$ & $\mathrm{LEF}$ & -12.316 & -0.484 & 11.832 & -0.127 & 0.140 & 0.267 & 44.315 \\
\hline 6 & $\mathrm{LEF}$ & $\mathrm{H} 2 \mathrm{O}$ & -9.246 & 4.059 & 13.305 & -0.135 & 0.171 & 0.306 & 43.480 \\
\hline 7 & $\mathrm{H}_{2} \mathrm{O}$ & $\mathrm{O}_{2}$ & -12.316 & -0.982 & 11.334 & -0.127 & 0.138 & 0.265 & 42.770 \\
\hline 8 & $\mathrm{LEF}$ & $\mathrm{LEF}$ & -9.246 & -0.484 & 8.762 & -0.135 & 0.140 & 0.275 & 31.862 \\
\hline 9 & $\mathrm{LEF}$ & $\mathrm{O}_{2}$ & -9.246 & -0.982 & 8.264 & -0.135 & 0.138 & 0.273 & 30.271 \\
\hline
\end{tabular}

The initiation and monitoring practices of rheumatologists in Australia using LEF were also evaluated. The choice of the initial dose of LEF among the Australian rheumatologists who responded varied considerably. [10] Other researchers studied the profile of side effects and survival characteristics of LEF used in a regional population of patients in New Zealand (NZ). They concluded that their studies suggest a better profile of side effects and better survival of the drug for LEF than suggested by previous studies with a survival comparable to that of methotrexate.

\section{MATERIALS AN METHODS}

We obtained the information about the collagen of "The National Center for Biotechnology" Information (NCBI): LOCUS CO2A1_HUMAN 1487 aa linear PRI 10-OCT2018 DEFINITION Rec Name: Full=Collagen alpha-1(II) chain; Alt Name: Full=Alpha-1 type II collagen; 
Contains: Rec Name: Full=Collagen alpha-1(II) chain; Contains: Rec Name: Full=Chondrocalcin; Flags: Precursor. ACCESSION P02458 VERSION P02458.3 DBSOURCE Uni Prot KB: locus CO2A1_HUMAN, accession P02458; class: standard.

We obtained the formula of the LEF on the page of PubChem figure1.

In Figure 2 the graph is presented. You can see that Gly is the most abundant amino acid of all its structural composition; while Trp is the amino acid with fewer units.

In Table 1 it can be seen that the lowest value of ETC corresponds to the $\mathrm{LEF}-\mathrm{O}_{2}$ interaction; This means that the LEF is easily oxidized. It can also be seen that the LEF- $\mathrm{H}_{2} \mathrm{O}$ interaction is not as deep in the quantum well; this indicates that the LEF is not very soluble in water.

Table 2 shows the calculations of two new concepts. The quantum molecular impedance is relative to water (QMIRW) and the quantum molecular conductance relative to water (QMCRW). With these two concepts, the reader will better understand the concept of ETC.

We can observe in this table 2 that the LEF-O2 interaction has almost half the value of the valence electron jump impedance of LEF towards $\mathrm{O}_{2}$ than the jump of $\mathrm{H}_{2} \mathrm{O}$ to another molecule of $\mathrm{H}_{2} \mathrm{O}$. With the conductance, the opposite happens.
The quantum calculations we carry out with the hyperchem software. These calculations were made in other articles already published by us. [11-15]

\section{RESULTS AND DISCUSSIONS}

We characterize human glycogen with the software model 6000. [18] Information on the sequencing of this protein was taken from the NCBI database.

Table.2: Calculation of MQIRW and MQCRW.

This calculation is based on the ETCs in Table 1.

\begin{tabular}{|c|c|c|c|c|}
\hline No & $\begin{array}{c}\text { Reducin } \\
\mathbf{g} \\
\text { agent }\end{array}$ & $\begin{array}{c}\text { Oxidizin } \\
\text { g } \\
\text { agent }\end{array}$ & $\begin{array}{c}* \text { MQIR } \\
\text { W }\end{array}$ & $\begin{array}{c}* * \text { MQCR } \\
\text { W }\end{array}$ \\
\hline 1 & $\mathrm{O}_{2}$ & $\mathrm{H}_{2} \mathrm{O}$ & 1.288 & 0.776 \\
\hline 2 & $\mathrm{O}_{2}$ & $\mathrm{LEF}$ & 1.048 & 0.954 \\
\hline 3 & $\mathrm{O}_{2}$ & $\mathrm{O}_{2}$ & 1.008 & 0.992 \\
\hline 4 & $\mathrm{H}_{2} \mathrm{O}$ & $\mathrm{H}_{2} \mathrm{O}$ & 1 & 1 \\
\hline 5 & $\mathrm{H}_{2} \mathrm{O}$ & $\mathrm{LEF}$ & 0.806 & 1.240 \\
\hline 6 & $\mathrm{LEF}$ & $\mathrm{H} 2 \mathrm{O}$ & 0.791 & 1.264 \\
\hline 7 & $\mathrm{H} 2 \mathrm{O}$ & $\mathrm{O}_{2}$ & 0.778 & 1.285 \\
\hline 8 & $\mathrm{LEF}$ & $\mathrm{LEF}$ & 0.580 & 1.725 \\
\hline 9 & $\mathrm{LEF}$ & $\mathrm{O}_{2}$ & 0.551 & 1.815 \\
\hline
\end{tabular}

*Molecular quantum impedance relative to water (MQIRW) **Molecular quantum conductance relative to water (MQCRW) The QMIRW and the QMCRW should not be confused with traditional impedance and conductance.

These concepts are similar; but, not the same.

Table.3: This table shows the 13 most likely and strongest interactions of 40 calculated.

\begin{tabular}{|c|c|c|c|c|c|c|c|c|c|}
\hline No. & $\begin{array}{c}\text { Reducing } \\
\text { agent }\end{array}$ & $\begin{array}{c}\text { Oxidizing } \\
\text { agent }\end{array}$ & HOMO & LUMO & BG & E- & E+ & EP & ETC \\
\hline 13 & LEF & Thr & -9.246 & 0.832 & 10.078 & -0.135 & 0.191 & 0.326 & 30.914 \\
\hline 12 & LEF & Lys & -9.246 & 0.943 & 10.189 & -0.135 & 0.195 & 0.330 & 30.875 \\
\hline 11 & LEF & Pro & -9.246 & 0.792 & 10.038 & -0.135 & 0.191 & 0.326 & 30.791 \\
\hline 10 & LEF & Gln & -9.246 & 0.755 & 10.001 & -0.135 & 0.192 & 0.327 & 30.584 \\
\hline 9 & LEF & Asn & -9.246 & 0.644 & 9.890 & -0.135 & 0.193 & 0.328 & 30.153 \\
\hline 8 & LEF & Ser & -9.246 & 0.565 & 9.811 & -0.135 & 0.198 & 0.333 & 29.462 \\
\hline 7 & LEF & Arg & -9.246 & 0.558 & 9.804 & -0.135 & 0.199 & 0.334 & 29.353 \\
\hline 6 & LEF & Tyr & -9.246 & 0.293 & 9.539 & -0.135 & 0.193 & 0.328 & 29.081 \\
\hline 5 & $*$ LEF & $*$ Glu & -9.246 & 0.438 & 9.684 & -0.135 & 0.201 & 0.336 & 28.822 \\
\hline 4 & $*$ LEF & $*$ Met & -9.246 & 0.145 & 9.391 & -0.135 & 0.192 & 0.327 & 28.719 \\
\hline 3 & $*$ His & $*$ LEF & -9.307 & -0.484 & 8.823 & -0.169 & 0.14 & 0.309 & 28.555 \\
\hline 2 & $*$ LEF & $*$ Asp & -9.246 & 0.420 & 9.666 & -0.135 & 0.204 & 0.339 & 28.514 \\
\hline 1 & $*$ Arg & $*$ LEF & -9.176 & -0.484 & 8.692 & -0.165 & 0.14 & 0.305 & 28.499 \\
\hline
\end{tabular}

*These interactions are the five highest and strongest probability anchor points of the 41 calculated.

In Table 3, we can see the 13 interactions of 40 calculated. These 13 interactions show that only 2 of them are oxidant and the other 11 are reductive. The five most reliable and most probable interactions of these are 
indicated with one *. Within these five interactions are the interactions of the LEF with His and Arg in oxidizing form. Therefore, these LEF interactions are the most dangerous because they are oxidants.

\section{CONCLUSIONS}

In Table 4, we summarize the most significant interactions for LEF anchors in collagen amino acids.

Table.4: Summary of the most significant interactions.

\begin{tabular}{|c|c|c|c|l|}
\hline Number & AA & Units & Percentages & \multirow{2}{*}{ Oxidative } \\
anchoring (1)
\end{tabular}

The numbers placed in parentheses indicate their position in table 3 .

The research hypotheses were fulfilled. Next they are enunciated with details.

Hypothesis 1: LEF interacts with collagen through its amino acids.

Yes, these 13 of 40 interactions (Table 3) show that only two of them are oxidant and the other 11 are reductive (antioxidant).
Hypothes is 2: LEF has a positive influence on arthritis. According to hypothesis 1. Two of 40 Interactions are oxidants, 13 of the interactions that have the lowest ETC and high to medium probability are reducing (antioxidants). Therefore, it is concluded that LEF is more beneficial than malignant.

Hypothesis 3: Quantum chemistry determines the type of interaction of LEF with the amino acids of collagen.

Yes, all interactions were calculated using the hyperchem software using the SE-PM3 method.

\section{REFERENCES}

[1] Firmin H. Aikpo, Miriac Dimitri S. Ahouanse, Lucien Agbandji, Patrick A. Edorh, Christophe S. Houssou (2017). Assessment of contamination of soil by pesticides in Djidja's cotton area in Benin. International Journal of Advanced Engineering Research and Science (ISSN: 2349-6495(P) | 24561908(O)), 4(7), 001-005. http://dx.doi.org/10.22161/ijaers.4.7.1

[2] Perfect, T. J., \& Schwartz, B. L. (Eds.) (2002). Applied metacognition Retrieved from http://www.questia.com/read/107598848

[3] Myers, D. G. (2007). Psychology(1stCanadian ed.). New York, NY: Worth.

[4] Cognition.(2008). In Oxford reference online premium dictionary. Retrieved from http://www.oxfordreference.com

[5] Blue, L. (2008, March 12).Is our happiness preordained? [Online exclusive]. Time. Retrieved from http://www.time.com/time/health

[6] J. Clerk Maxwell (1892), A Treatise on Electricity and Magnetism, 3rd ed., vol. 2. Oxford: Clarendon, pp.68-73.

[7] Morgan Schultz, Stephanie O, Keeling, Steven J Kate, Walter P Maksymowych, Dean T Eurich y Jill J Hall. (2017). Clinical effectiveness and safety of leflunomide in inflammatory arthritis: a report from the RAPPORT database with supporting patient survey. doi: 10.1007/s 10067-017-3687-5.

[8] Qing Zhang, Yongqiang Ji, Wei Lv, Tianwei He y Jianping Wang. (2015). Protective effects of leflunomide on renal lesions in a rat model if diabetic nephropathy. doi: 10.3109/0886022X.2015.1105024.

[9] Zeb S, Wazir N, Waqas M, Taqweem A. (2016). Comparison of short-term efficacy of leflunomide and methotrexate in active Rheumatoid arthritis. J Postgrad Med Inst; 30(2): 177-80.

[10] Zhitao Feng,1,2,3,4 Juan Xu,5,6 Guochao He,7 Meiqun Cao,3,4 Lihong Duan,3,4 Liguo Chen,1 and Zhengzhi Wu2,3,4. (2016). Review Article The Efficacy and Safety of the Combination of Total 
Glucosides of Peony and Leflunomide for the Treatment of Rheumatoid Arthritis: A Systemic Review and Meta-Analysis. Hindawi Publishing Corporation Evidence-Based Complementary and Alternative Medicine, 2016, 22.

[11] González-Pérez, M. (2017). Quantum Theory of the Electron Transfer Coefficient. International Journal of Advanced Engineering, Management and Science, 3(10).

[12] González-Pérez, M., Gonzalez-Martinez, D., González-Martínez, E. L., Pacheco-Bautista, D., \& Medel-Rojas, A. (2018). Theoretical-ChemicalQuantum Analisys of Sarin Neurotoxicity. World Journal of Pharmacy and Pharmaceutical Sciences, 7(5), 173-180.

[13] García-Aguilar, K., Herrera-Cantú, I., Pedraza-Gress, E., Flores-Gonzalez, L. A., Aparicio-Razo, M., Sánchez-Parada, O., ... \& González-Pérez, M. Quantic Analysis of Formation of a Biomaterial of Latex, Retinol, and Chitosan for Biomedical Applications. International Journal of Advanced Engineering, Management and Science, 4(1).

[14] Herrera-Cantú, I., García-Aguilar, K., Pedraza-Gress, E., Vázquez, E., García-Mar, J. J., Flores-González, L. A., ... \& González-Pérez, M. Quantic Analysis of the Adherence of a Gram-Negative Bacteria in A HEPA Filter. International Journal of Advanced Engineering, Management and Science, 3(12).

[15] González-Pérez, M. (2017). Chemical-quantum Analysis of the Aggressiveness of Glucose and its Appeasement with ATP Inside the Cell, and Water as an Excellent Antioxidant. World Journal of Pharmacy and Pharmaceutical Sciences, 6(4), 95-99.

[16] Pacheco-García, P. F., Perez-Gonzalez, A., RamosFlores, A., Flores-Gonzalez, L. A., Lopez-Oglesby, J. M., \& Gonzalez-Perez, M. Experimental study and calculation of the electron transfer coefficients on the dissolution behavior of chitosan in organic acids. International Journal of Advanced Engineering, Management and Science, 3(6).

[17] González-Perez, M. (2017). Interactions analysis of four chemotherapeutic drugs vs. nitrogenous bases of DNA and RNA, using quantum methods. World Journal of Pharmaceutical Research, 5(6), 309-320.

[18] González-Pérez, M. Eletron Transfer Coefficient (ETC) DATA of Amino Acids https://www.researchgate.net/publication/324102871 _ETC_DATA_OF_AMINO_ACIDS. DOI: 10.13140/RG.2.2.20316.49281. 